\title{
Influência da temperatura e da quantidade de água no substrato sobre a germinação de sementes de Ochroma pyramidale (Cav. ex Lam.) Urban (pau-de- balsa) ${ }^{1}$
}

Michele Braule Pinto RAMOS²; Vania Palmeira VARELA²; Maria de Fátima Figueiredo MELO ${ }^{3}$

\begin{abstract}
RESUMO
O presente trabalho foi conduzido com o objetivo de avaliar diferentes volumes de água no substrato e temperaturas na germinação de sementes de Ochroma pyramidale (Cav. ex Lam.) Urban. Antes da instalação dos testes de germinação, as sementes foram tratadas com imersão em água quente a $80^{\circ} \mathrm{C}$ até o resfriamento, para superar a dormência. A semeadura foi realizada em rolos de papel germitest, umedecidos com volumes $(\mathrm{mL})$ de água equivalentes a 1,5; 2,0; 2,5 e 3,0 vezes o peso do substrato nas temperaturas de $25,30 \mathrm{e} 35^{\circ} \mathrm{C}$. O delineamento experimental adotado foi o inteiramente casualizado com os tratamentos em esquema fatorial $4 \times 3$. Para cada tratamento, utilizaram-se quatro repetições de 25 sementes. Após o encerramento do experimento (aos 21 dias), foi avaliada a porcentagem, o índice de velocidade de germinação e os comprimentos da raiz primária e do hipocótilo. A porcentagem de germinação final não foi influenciada pelos fatores estudados. O índice de velocidade de germinação foi favorecido pelas maiores temperaturas, $30 \mathrm{e} 35^{\circ} \mathrm{C}$. A temperatura de $30^{\circ} \mathrm{C}$ e a quantidade de água de 1,5 vezes o peso do papel, e $35^{\circ} \mathrm{C}$ e a quantidade de 3,0 vezes, foram as mais indicadas para o desenvolvimento da raiz primária e do hipocótilo da espécie. Para a germinação das sementes de $O$. pyramidale recomenda-se a temperatura de $30^{\circ} \mathrm{C}$ com a quantidade de água de 1,5 vezes o peso do papel, e a temperatura de $35^{\circ} \mathrm{C}$ com a quantidade de água de 3,0 vezes.
\end{abstract}

PALAVRAS-CHAVES

Volume de água, sementes florestais, Amazônia Central.

\section{Influence of temperature and substrate moisture on seed germination of Ochroma pyramidale (Cav. ex Lam.) Urban (balsa wood).}

\begin{abstract}
This work was carried out to evaluate the effects of different temperature levels and water contents in the substrate on the germination of Ochroma pyramidale (Cav. ex Lam.) Urban. Prior to the germination tests, all seeds were immersed in hot water $\left(80^{\circ} \mathrm{C}\right)$ to overcome the dormancy. Then, they were left on germitest paper, which were wetted using volume ( $\mathrm{mL}$ ) of water equivalent to 1.5, 2.0, 2.5 and 3 times the weight of the substrate, at temperature levels of 25,30 and $35^{\circ} \mathrm{C}$. The experimental design used was a completely randomized in a $4 \times 3$ factorial with four replicates of 25 seeds per treatment. Twenty-one days after germination tests started, the following variables were analyzed: germination percentage, germination speed and the length of primary roots and bypocotyle. The percentage of germination was not influenced by the studied factors. Higher temperatures, 30 and $35^{\circ} \mathrm{C}$, increased the speed rate of germination. At $30^{\circ} \mathrm{C}$, combined with water content equivalent to 1,5 times the paper weight, and at $35^{\circ} \mathrm{C}$ with 3,0 times, resulted in higher development to root and bypocotyle length.
\end{abstract}

\section{KEYWORDS}

Water volume, forest seeds, Central Amazonia.

\footnotetext{
${ }^{1}$ Pesquisa financiada pela FAPEAM (www.fapeam.am.gov.br)

${ }^{2}$ M.Sc., Instituto Nacional de Pesquisas da Amazônia (INPA/CPST), Cx. Postal 478, CEP 69060-001, Manaus-AM, e-mail: mbraule@inpa.gov.br, vaniav@inpa.gov.br ${ }^{3}$ M.Sc., INPA/CPBO, ffmelo@inpa.gov.br.
} 


\section{INTRODUÇÃO}

A exploração intensiva da floresta amazônica tem ocasionado a perda de recursos florestais valiosos e contribuído para a redução da base genética de inúmeras espécies. Desta forma, com o objetivo de subsidiar os estudos de reflorestamento, são necessárias pesquisas referentes à propagação das sementes dessas espécies.

Entre as espécies arbóreas com potencialidade de uso para reflorestamento na região destaca-se Ochroma pyramidale (Cav. ex Lam.) Urban (Pau-de-balsa) que, segundo Vasquez-Yanes (1974) apresenta grande importância ecológica como pioneira, além de possuir reconhecido valor econômico (Loureiro et al., 1979).

Os limites da temperatura de germinação fornecem informações de interesses biológico e ecológico, auxiliando os estudos ecofisiológicos e de sucessão vegetal (Labouriau \& Pacheco, 1978; Figliolia et al., 1993). Da mesma forma que a temperatura, a umidade do substrato constitui um dos fatores essenciais para desencadear o processo de germinação (Marcos Filho, 1986; Carvalho \& Nakagawa, 2000).

Pesquisas sobre as exigências de água em sementes são incipientes, estando disponíveis informações sobre a espécie florestal angelim-pedra, Dinizia excelsa (Mesquita, 2004) e algumas espécies agrícolas (Phaneendranath, 1980; Tanaka et al., 1991; Menezes at al., 1993; Novembre \& Marcos Filho, 1999; Gentil \& Torres, 2001).

Estudos disponíveis na literatura sobre as sementes de $O$. pyramidale referem-se às temperaturas ótimas para germinação (Souza et al., 2000) e aos mecanismos para superar a dormência (Varela \& Ferraz, 1991; Barbosa et al. 2004). Porém, não existem informações referentes a influência da quantidade de água no substrato e da temperatura sobre a germinação desta espécie. Portanto, levando em consideração sua importância ecológica, bem como sua potencialidade econômica na região, o presente trabalho visou avaliar a influência de diferentes volumes de água e temperaturas sobre a germinação de $O$. pyramidale.

\section{MATERIAL E MÉTODOS}

Os frutos de O. pyramidale foram coletados em 15/07/04 de uma árvore matriz na Estação Experimental de Silvicultura Tropical (EEST-INPA), no Km 45 da rodovia BR 174, em Manaus, Amazonas (02³3'00"S e 6002'22"W).

Após o beneficiamento manual, as sementes foram imersas em água quente a $80^{\circ} \mathrm{C}$ até o resfriamento para superar a dormência (Barbosa et al., 2004). O teste de germinação foi conduzido em rolos de papel germitest, umedecidos com volumes de água $(\mathrm{mL})$ equivalentes a 1,5; 2,0; 2,5; e 3,0 vezes o peso do substrato (g) sem adição posterior de água, com três folhas/rolo e acondicionados em sacos plásticos transparentes de 0,04 mm de espessura. Em seguida, os rolos foram colocados em câmaras de marca Fanem nas temperaturas constantes de $25,30 \mathrm{e} 35^{\circ} \mathrm{C}$, com fotoperíodo de 12 horas e fase luminosa de $10 \mu \mathrm{mol} . \mathrm{m}^{-2} \cdot \mathrm{s}^{-1}$ de radiação PAR (radiação fotossinteticamente ativa).
As avaliações foram efetuadas diariamente após a instalação do teste, sendo calculadas a porcentagem final de germinação e o índice de velocidade de germinação (IVG) (Maguire, 1962). Após o encerramento do experimento (aos 21 dias), foi avaliado o comprimento da raiz primária e do hipocótilo, com auxílio de régua milimetrada, tomando-se, aleatoriamente, dez plântulas para cada tratamento.

O delineamento experimental adotado foi o inteiramente casualizado em esquema fatorial $4 \times 3$, com quatro repetições de 25 sementes para cada tratamento. Os dados em porcentagem foram transformados em $\operatorname{arcsen} \sqrt{X / 100}$ para efeito de análise. As médias foram comparadas pelo teste de Tukey, a 5\% de probabilidade. Para os dados de comprimento da raiz primária e do hipocótilo, utilizou-se regressão com ajuste de função polinomial.

\section{RESULTADOS E DISCUSSÃO}

Os resultados obtidos com as sementes de $O$. pyramidale indicaram que não houve interação entre os fatores volumes de água e temperaturas sobre as porcentagens de germinação, tendo em vista que foram obtidas altas taxas de germinação em todos os tratamentos testados (Tabela 1). Estes resultados estão de acordo com os mencionados por Mesquita (2004) para Dinizia excelsa (angelim-pedra), e por Tanaka et al. (1991) para Arachis bypogaea (amendoim), segundo os quais as diferentes quantidades de água no substrato não influem significativamente nas porcentagens de germinação. Segundo Vicente et al. (1969), a germinação mais favorável pode não ser induzida por somente um volume de água, mas por diversos volumes que ocupam uma faixa de amplitude específica conforme a espécie. Entretanto, experimentos realizados por Gentil \& Torres (2001) com sementes de Cucumis anguria (maxixe), e por Menezes et al. (1993) C. sativus (pepino), $C$. melo (melão) e Citrullus lanatus (melancia) mostraram que o umedecimento do substrato com o volume de água de 3,0 vezes o peso do papel foi desfavorável ao processo de germinação.

Os resultados de índice de velocidade de germinação (IVG), não apresentaram diferença significativa para as quantidades

Tabela 1 - Médias das porcentagens de germinação de sementes de Ochroma pyramidale obtidas sob três temperaturas e quatro quantidades de água no substrato.

\begin{tabular}{|c|c|c|c|c|}
\hline \multirow{2}{*}{$\begin{array}{l}\text { Quantidade de água } \\
\text { no substrato }(\mathrm{mL} / \mathrm{g})\end{array}$} & \multicolumn{3}{|c|}{ Temperatura $\left({ }^{\circ} \mathrm{C}\right)$} & \multirow[b]{2}{*}{ Médias } \\
\hline & 25 & 30 & 35 & \\
\hline 1,5 & 81 & 70 & 85 & 79 \\
\hline 2,0 & 73 & 78 & 80 & 77 \\
\hline 2,5 & 76 & 81 & 76 & 78 \\
\hline 3,0 & 78 & 82 & 84 & 82 \\
\hline Médias & 77 & 79 & 81 & \\
\hline
\end{tabular}

$C V=8,7 \% ; F_{t}=1,29^{\text {ns }} ; F_{q}=1,22^{\text {ns }} ; F_{\text {txq }}=1,79^{\text {ns }}$

ns - não significativo para temperatura, quantidade de água e interação. 


\section{ACTA \\ AMAZONICA}

INFLUÊNCIA DA TEMPERATURA E DA QUANTIDADE DE ÁGUA NO SUBSTRATO SOBRE A GERMINAÇÃO DE SEMENTES DE Ochroma pyramidale (CAV. EX LAM.) URBAN (PAU-DE-BALSA) de água no substrato. No entanto, ocorreu diferença para a temperatura, sendo que as maiores temperaturas foram mais favoráveis ao processo (Tabela 2). Resultados semelhantes foram obtidos para as sementes de $D$. excelsa, que apresentaram bom desempenho para uma ampla faixa de volume de água (Mesquita, 2004).

O comprimento da raiz primária foi influenciado pela quantidade de água no substrato (Figura 1). Nas temperaturas de $25 \mathrm{e} 35^{\circ} \mathrm{C}$, à medida que se elevou a quantidade de água no substrato, o comprimento da raiz primária foi favorecido. Entretanto, a $25^{\circ} \mathrm{C}$ foram observados resultados inferiores quando comparados com as demais temperaturas. Os maiores comprimentos de raiz primária foram observados $a 30^{\circ} \mathrm{C}$ para a quantidade de água de 1,5 vezes o peso do papel e $35^{\circ} \mathrm{C}$ com 2,5 e 3,0 vezes. Na literatura consultada são praticamente inexistentes as informações sobre comprimento da raiz primária e do hipocótilo relacionadas com o umedecimento do substrato em sementes de espécies florestais, portanto a discussão se limitará à comparação dos resultados obtidos com a única referência disponível. O comportamento

Tabela 2 - Médias do índice de velocidade de germinação (IVG) das sementes de Ocbroma pyramidale obtidas sob três temperaturas e quatro quantidades de água no substrato.

\begin{tabular}{lllll}
\hline \hline \multirow{2}{*}{$\begin{array}{l}\text { Quantidade de água } \\
\text { no substrato }(\mathrm{mL} / \mathrm{g})\end{array}$} & \multicolumn{4}{l}{ Temperatura $\left({ }^{\circ} \mathrm{C}\right)$} \\
\cline { 2 - 5 } & $\mathbf{2 5}$ & $\mathbf{3 0}$ & $\mathbf{3 5}$ & Médias \\
\hline $\mathbf{1 , 5}$ & 2,80 & 3,53 & 4,08 & 3,47 \\
2,0 & 2,63 & 4,00 & 4,13 & 3,59 \\
2,5 & 3,08 & 4,03 & 3,80 & 3,64 \\
3,0 & 2,90 & 3,88 & 4,05 & 3,61 \\
Médias & $\mathbf{2 , 8 5}$ b & $\mathbf{3 , 8 6}$ a & $\mathbf{4 , 0 2}$ & \\
\hline \hline
\end{tabular}

$\mathrm{CV}=13,7 \% ; \mathrm{F}_{\mathrm{t}}=26,7^{* *} ; \mathrm{F}_{\mathrm{q}}=0,3^{\text {ns }} ; \mathrm{F}_{\mathrm{txq}}=0,8^{\text {ns }}$

** - significativo a $1 \%$ de probabilidade.

ns - não significativo para quantidade de água e interação.

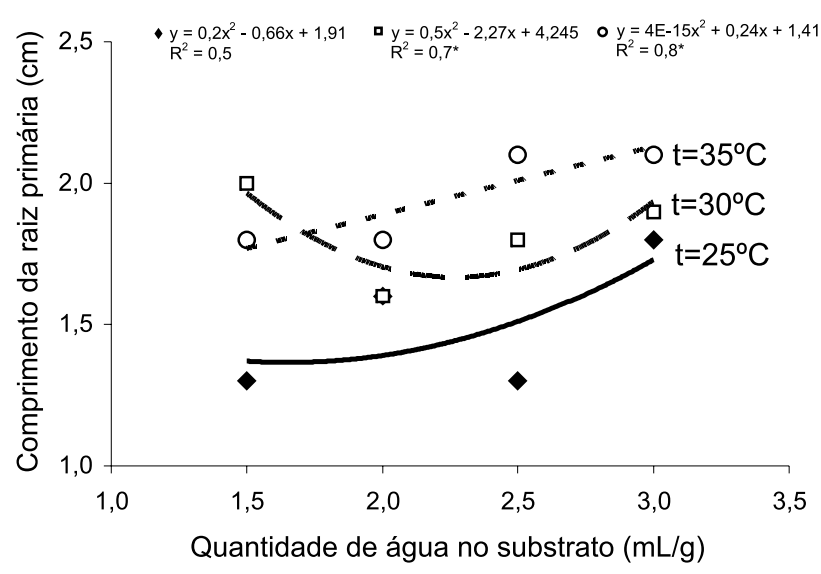

Figura 1 - Comprimento da raiz primária $(\mathrm{cm})$ de sementes de Ochroma pyramidale germinadas sob três temperaturas e quatro quantidades de água no substrato. $\mathrm{t}=$ temperatura. *significativo. observado para O. pyramidale foi similar ao encontrado para o comprimento da raiz primária de $D$. excelsa a $30^{\circ} \mathrm{C}$ com a quantidade de água de 1,5 vezes o peso do papel e a $35^{\circ} \mathrm{C}$ com 2,5 vezes (Mesquita, 2004).

Os resultados de comprimento do hipocótilo foram influenciados pelas temperaturas e quantidades de água no substrato (Figura 2). Na temperatura de $30^{\circ} \mathrm{C}$, o comprimento do hipocótilo foi superior quando comparado com as demais. Nesta temperatura, os melhores resultados foram observados para as quantidades de água de 1,5, 2,0 e 2,5 vezes o peso do papel, com valores de 2,4, 2,5 e 2,2 cm, respectivamente. Por outro lado, a temperatura mais prejudicial para o desenvolvimento do hipocótilo foi $25^{\circ} \mathrm{C}$. Resultados semelhantes foram obtidos para sementes de $D$. excels $a$, nos quais as temperaturas de 30 e $35^{\circ} \mathrm{C}$ favoreceram o desenvolvimento do hipocótilo (Mesquita, 2004).

\section{CONCLUSÕES}

A porcentagem de germinação das sementes de $O$. pyramidale não foi influenciada pelas temperaturas, quantidades de água no substrato e interação entre esses fatores.

Para o índice de velocidade de germinação, as temperaturas de $30 \mathrm{e} 35^{\circ} \mathrm{C}$ foram as mais favoráveis.

Para o desenvolvimento da raiz primária e do hipocótilo das plântulas de $O$. pyramidale, a temperatura de $30^{\circ} \mathrm{C}$ e a quantidade de água de 1,5 vezes o peso do papel, e a temperatura de $35^{\circ} \mathrm{C}$ e a quantidade de água de 3,0 vezes, constituem os melhores tratamentos.

\section{AGRADECIMENTOS}

Expressamos nossos sinceros agradecimentos ao Técnico Agrícola Lúcio Flávio Pereira Batalha pelo auxílio na coleta de

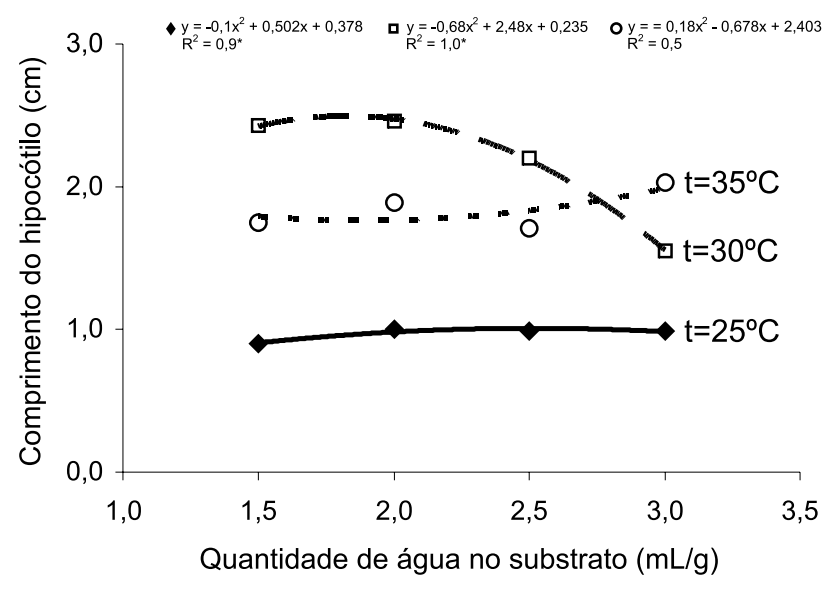

Figura 2 - Comprimento do hipocótilo (cm) de sementes de Ochroma pyramidale germinadas sob três temperaturas e quatro quantidades de água no substrato. $\mathrm{t}=$ temperatura. *significativo. 


\section{ACTA AMAZONICA}

INFLUÊNCIA DA TEMPERATURA E DA QUANTIDADE DE ÁGUA NO SUBSTRATO SOBRE A GERMINAÇÃO DE SEMENTES DE Ochroma pyramidale (CAV. EX LAM.) URBAN (PAU-DE-BALSA) dados, ao Pesquisador Niro Higuchi pelo auxílio na elaboração do Abstract e ao Doutorando Arlem Nascimento de Oliveira pela ajuda na elaboração do texto.

\section{BIBLIOGRAFIA CITADA}

Barbosa, A.B.; Sampaio, P.T.B.; Campos, M.A.A.; Varela, V.P.; Gonçalves, C. de B.A. 2004. Tecnologia alternativa para a quebra de dormência das sementes de pau-de-balsa (Ochroma lagopus Sw., Bombacaceae). Acta Amazonica, 34(1):107-110.

Carvalho, N.M.; Nakagawa, J. 2000. Sementes: ciência, tecnologia e produção. FUNEP, Jaboticabal. 588pp.

Gentil, D.F.; Torres, S.B. 2001. Umedecimento do substrato e germinação de sementes de maxixe (Cucumis anguria L.). Revista Brasileira de Sementes, 23(2):113-116.

Figliolia, M.B.; Oliveira, E.C.; Piña-Rodrigues, F.C.M. 1993. Análise de semente. In: Aguiar, I.B.; Piña-Rodrigues, F.C.M.; Figliolia, M.B. (Eds). Sementes florestais tropicais. ABRATES, Brasília. p.137-174.

Labouriau, L.G.; Pacheco, A. 1978. On the frequency of isothermal temperature germination in seeds of Dolichos biflorus L. Plant \& Cell Physiology, 19:507-512.

Loureiro, A.A.; Silva, M.F.; Alencar, J.C. 1979. Essências madeireiras da Amazônia. Vol.2. Instituto Nacional de Pesquisas da Amazônia, Manaus. 187pp.

Maguire, J.O. 1962. Speed of germination: Aid in selection and evaluation for seedling emergence and vigor. Crop Science, 2(2): 176-177.

Marcos Filho, J. 1986. Germinação de sementes. In: Semana de Atualização em Sementes, 1. Fundação Cargill, Campinas. p.11-39.

Menezes, N.L.; Silveira, T.D.L.; Storck, L. 1993. Efeito do nível de umedecimento do substrato sobre a germinação de Curcubitaceas. Ciência Rural, 23(2):157-160.

Mesquita, L.G. 2004. Aspectos tecnológicos e morfológicos da germinação de sementes de Angelim-pedra (Dinizia excelsa Ducke.). Monografia, Instituto de Tecnologia da Amazônia (UTAM), Manaus, Amazonas. 44p.

Novembre, A.D.L.C.; Marcos Filho, J. 1999. Estudo da metodologia para condução do teste de germinação em sementes de algodão deslintadas mecanicamente. Revista Brasileira de Sementes, 21(2): 187-193.

Phaneendranath, B.R. 1980. Influence of amount of water in the paper towel on standard germination tests. Journal of Seed Technology, 5(2): 82-87.

Souza, M.A.S.M.; Varela, V.P.; Ferraz, I.D.K. 2000. Influência de diferentes temperaturas na germinação de sementes de espécies florestais da Amazônia. I. Pau-de-balsa (Ocbroma pyramidale (Cav. Ex. Lam.) Urban). II. Faveira-orelha-demacaco (Enterolobium schomburgkii Benth.) In: IX Jornada de Iniciação Científica do INPA, Manaus. Anais. p. 255-258.

Tanaka, M.A.S.; Mariano, M.I.A.; Leão, N.V.M. 1991. Influência da quantidade de água no substrato sobre a germinação de sementes de amendoim. Revista Brasileira de Sementes, 13(1): 73-76.

Varela, V.P.; Ferraz, I.D.K. 1991. Germinação de sementes de pau-de-balsa. Pesquisa Agropecuária Brasileira, 26(10):1685-1689.

Vasquez-Yanes, C. 1974. Estudies on the germination of seeds of Ochroma lagopus Startz. Turrialba, 24(2):176-179.

Vicente, A.M; Noronha, A.; Silberschmidt, K. 1969. Substrate moisture levels for germination testing of some agricultural seeds. Anais da Academia Brasileira de Ciências, 41(4):633639.

\section{RECEBIDO EM 11/02/2005 ACEITO EM 16/12/2005}

